\title{
Previsão do ruído ambiental urbano devido à implantação do Modal Veículo Leve sobre Trilhos (VLT) por meio de simulação computacional
}

\author{
Environmental urban noise prediciting due to Light Rail Vehicle (VLT) \\ implementation by computational simulation
}

\section{Prévision de l'environnement urbain du Bruit Due Tramway (VLT) utilisation simulation computationnele}

\section{Predicción del ruido urbano debido a la implementación del Sistema de Tren Eléctrico Urbano (VLT) por medio de simulación computacional}

\author{
Adriana Eloá Bento Amorim ${ }^{1}$ \\ Luciane Cleonice Durante ${ }^{1}$ \\ Jhonatha Correia Vilela ${ }^{1}$ \\ Ivan Julio Apolônio Callejas ${ }^{1}$
}

Recebido em 27/10/2016; revisado e aprovado em 26/04/2017; aceito em 10/05/2017

DOI: http://dx.doi.org/10.20435/inter.v18i4.1425

\begin{abstract}
Resumo: O trabalho avaliou os impactos da implantação do Veículo Leve sobre Trilhos (VLT) no ruído ambiental de um corredor estrutural viário do aglomerado urbano de Cuiabá-Várzea Grande/MT, Brasil. Utilizando simulação computacional, concluiu-se que, muito embora, a implantação do VLT proporcione redução do ruído ambiental, este ainda permanece acima do limite normativo, indicando a necessidade de adoção de gestão integrada para mitigação da poluição sonora urbana.
\end{abstract}

Palavras-chave: meio ambiente urbano; poluição sonora; ruído de tráfego. Abstract: The study aimed to evaluate the environmental noise impact of a Light Rail Vehicle (LRV)
implementation in an urban agglomeration roadway of Cuiabá-Várzea Grande/MT, Brazil. Using simulation
computer, the results showed that, the noise polution still remain above the criteria level, requiring
implementation of unified management strategies to mitigate the urban noise pollution.

Key words: urban environment; noise pollution; traffic noise.

Résumé: L'étude a évalué les effets de la mise du tramway dans le bruit ambiant d'un corridor structural de route de la zone urbaine de Cuiabá-Várzea Grande/MT, Brésil. En utilisant simulation de l'ordinateur, il a été conclu que, bien que la mise en œuvre du tramway fournit le bruit environnemental réduit, il reste encore au-dessus de la limite légale, ce qui indique la nécessité d’adopter une gestion intégrée pour l'atténuation de la pollution sonore en milieu urbain.

Mots-clés: environnement urbain; pollution sonore; le bruit de la circulation.

Resumen: El estudio evaluó los efectos del Sistema de Tren Eléctrico Urbano en el ruido ambiental de un corredor estructural en la zona urbana de Cuiabá, Várzea Grande / MT, Brasil. Mediante simulación por ordenador, se concluyó que, si bien la aplicación del Sistema de Tren Eléctrico Urbano proporciona ruido ambiental reducido, todavía se mantiene por encima del límite legal, lo que indica la necesidad de gestión integrada para la mitigación de la contaminación acústica urbana.

Palabras clave: medio ambiente urbano; poluición sonora; ruido del tráfico.

\section{INTRODUÇÃO}

Os centros urbanos configuram ambientes de exposição a elevados níveis de ruído (MELO et al., 2010; McALEXANDER, GERSHON, NEITZEL, 2015), nos quais a poluição sonora se apresenta como um dos maiores problemas de saúde pública (WHO, 1999; 2011; RODRIGUES; NASSI; KAHN, 2012) e causas de desconforto da comunidade (GERGES, 2000). Dentre as diversas fontes de ruído

\footnotetext{
${ }^{1}$ Universidade Federal de Mato Grosso, Cuiabá, Mato Grosso, Brasil.
} 
das cidades, destaca-se o tráfego veicular, composto por veículos leves (carros e motocicletas) e por veículos pesados (caminhões e ônibus).

Os ônibus são o modal de transporte coletivo predominante no Brasil. Devido à baixa qualidade dos serviços ofertados, esse sistema é pouco atrativo, sendo um dos fatores que contribuem para o elevado número de veículos leves circulantes, que trafegam em situação de baixa densidade de ocupação veicular. Nesse contexto, geram-se condições de congestionamento do tráfego, devido à incompatibilidade do fluxo com as caixas viárias e dessincronização dos sistemas semafóricos, o que exige constantes acelerações e frenagens, resultando em elevado ruído ambiental.

O ruído ambiental pode ser considerado como a superposição de ruídos, normalmente de naturezas diferentes e origens distintas, próximas ou remotas, não sendo nenhum deles objeto de avaliação. Representando uma das maiores fontes de ruído ambiental, o ruído de tráfego (rodoviário, ferroviário, aéreo) deve ser estimado quando do projeto novo ou intervenção de vias, "a fim de avaliar o impacto causado pelo ruído e nas comunidades ao entorno da via" (BISTAFA, 2011, p. 228). A pesquisa na área de ruído ambiental urbano é um tema consolidado no Brasil e com normativa nacional estabelecida na NBR 10.151 (ASSOCIAÇÃO BRASILEIRA DE NORMAS TÉCNICAS [ABNT], 2000), constatados em Nagem (2004), Cantieri et al. (2010), Cortêz e Niemeyer (2014), Maia (2016), Bressane et al. (2016), dentre outros.

Nunes (1999) considera o tráfego veicular como o maior contribuinte para o ruído ambiental urbano, classificando-o como pulsante, pelo fato de os veículos moverem-se com uma série de acelerações e desacelerações, desenvolvendo velocidades baixas e médias e acarretando níveis sonoros elevados em seus itinerários.

Intervenções que possibilitem o deslocamento do maior número de pessoas com a menor frota circulante possível são requeridas, pois contribuem para a redução do ruído do tráfego e, consequentemente, para melhoria da qualidade de vida da população. Atualmente, o Veículo Leve sobre Trilhos (VLT), modal de transporte urbano do tipo trem de passageiros de superfície, tem se apresentado como uma alternativa para o transporte de massa urbano (SANTOS et al., 2011).

Uma das vantagens apontadas pelo VLT é seu baixo nível de ruído operacional, devido ao baixo atrito gerado na passagem das rodas do trem sobre os trilhos. Segundo a ABNT (1997a; 1997b), os projetos de VLT devem garantir adequado conforto acústico aos passageiros, condutores e usuários que se encontram nas plataformas das estações, não produzindo níveis de ruído indesejáveis durante o seu funcionamento ou operação, inclusive para as pessoas nas regiões lindeiras às vias em que circula. No entanto, em seu deslocamento, realiza frenagens e acelerações que provocam excitação na superestrutura da via, o que, junto com as características do trecho (aclives, declives ou planos), gera ruído que é transmitido por via aérea e estrutural para as edificações vizinhas e para o interior dos carros, podendo causar, dependendo da intensidade e do tempo de exposição, desconforto e exposição da comunidade e dos usuários (LAGE, 2003). Além disso, o ruído ambiental urbano resultante da inserção do modal VLT depende da operacionalização da frota veicular já existente, podendo este constituir-se em uma nova fonte de ruído, com influência negativa no clima acústico nas regiões onde é implementado.

O potencial de redução do ruído ambiental urbano proporcionado pelo modal VLT, foi estudado no Brasil por Maroja et al. (2013) que analisaram o impacto acústico da implantação do modal VLT em Brasília-DF, em dois cenários, usando simulação computacional. No primeiro, apresentou, por meio de mapas acústicos, o ambiente sonoro da região, com o tráfego de 
veículos existente. No segundo, mostrou as alterações devidas à implantação do VLT e com a consideração de redução em $30 \%$ do tráfego de veículos. A comparação dos cenários indicou redução nos níveis de pressão sonora em aproximadamente $2 \mathrm{~dB}(\mathrm{~A})$, demostrando que o VLT, nessa condição de operação, não aumentaria os níveis de pressão sonora que já se encontravam $10 \mathrm{~dB}(\mathrm{~A})$ acima do nível permitido. Também por meio de simulações, a redução do fluxo de veículos pesados correspondeu à redução de níveis de pressão sonora (NPS) em corredores de transporte no Brasil e na Europa (JANIC; VLEUGEL, 2012; BUNN; ZANNIN, 2015).

Há mais de dez anos, o recurso da elaboração de mapas acústicos utilizando simulação computacional tem demonstrado ampla aplicação em pesquisas de ruído urbano no Brasil, com destaque para as cidades de: Aracaju, SE (GUEDES, 2005), Belém, PA (MIRANDA; MACEDO, 2014), Rio de Janeiro, RJ (MARDONES, 2009), Águas Claras, DF (GARAVELLI et al., 2013), Natal, RN (PINTO, 2013) e Curitiba, PR (ZANNIN; SANT'ANA, 2011; FIEDLER; ZANNIN, 2015).

Vale destacar a influência do relevo e da ocupação do solo urbano na propagação e intensificação dos efeitos e incômodos provocados pelo ruído, bem como do processo de verticalização. A modificação do perfil das ruas implica o aumento da contribuição no campo direto (consequência do aporte de tráfego) e do campo refletido, sobre as fachadas (CORTEZ; NIEMEYER, 2014). Entretanto edifícios verticais nem sempre irão criar ambientes urbanos do tipo cânion, pois a existência de recuos, de diferentes alturas e de descontinuidades entre as fachadas vizinhas também podem tornar o espaço permeável ao ruído, contribuindo para uma menor permanência e concentração dos raios refletidos (GUEDES, 2005).

Evidencia-se que a propagação do ruído urbano depende da configuração dos edifícios, e os mapas acústicos se apresentam com grande potencial de uso como ferramenta de apoio às decisões sobre planejamento e ordenamento do território. O diagnóstico do ruído ambiental pode fornecer informações para avaliação das emissões sonoras de infraestruturas de transporte existentes e de atividades econômicas ruidosas instaladas, identificando eventuais necessidades de implementação de medidas de redução de ruído. Já a simulação de cenários permite avaliar a influência sonora de futuras intervenções, possibilitando a escolha da alternativa de menor impacto (PINTO; GUEDES; LEITE, 2004; BISTAFA, 2011; BASTIÁN-MONARCA; ARENAS, 2016).

O objetivo geral é avaliar os impactos da implantação do Veículo Leve sobre Trilhos (VLT) no ruído ambiental, em corredor estrutural viário do aglomerado urbano de Cuiabá/Várzea Grande, Mato Grosso, Brasil, por meio de simulação computacional. No contexto dessa intervenção urbana, recorta-se com olhar pragmático a questão do ruído ambiental, uma vez que o projeto aponta como um dos seus benefícios, a redução da poluição sonora (SILVA et al., 2015). Assim, o estudo se justifica pelo fato de que a espacialidade do ruído depende da morfologia urbana, que o diferencia dos demais estudos já desenvolvidos para outras localidades, inserindo o ruído ambiental como uma relevante variável a ser abordada no contexto dos impactos da complexidade do empreendimento.

\section{METODOLOGIA}

O local do estudo foi o aglomerado urbano de Cuiabá/Várzea Grande, Mato Grosso, Brasil, onde se encontra em fase de implementação a Linha 1 do transporte modal Veículos Leves sobre Trilhos, com traçado no sentido Nordeste-Sudoeste (Figura 1). A intervenção urbana já realizada consistiu no alargamento do canteiro central da via existente, reduzindo-se o número de pistas 
laterais de tráfego destinado aos veículos leves e pesados (Figura 2). Com isso, o projeto prevê a total retirada de circulação dos ônibus coletivos da via, cuja integração ao novo modal se dá por meio de terminais híbridos, no início e fim da referida linha, que possui $15 \mathrm{~km}$ de extensão e 22 estações. Estimou-se, também, redução na frota de veículos de passeio, em função de estímulos à adesão da população ao novo modal, muito embora o percentual de redução não tenha sido estabelecido no anteprojeto (MATO GROSSO, 2012).

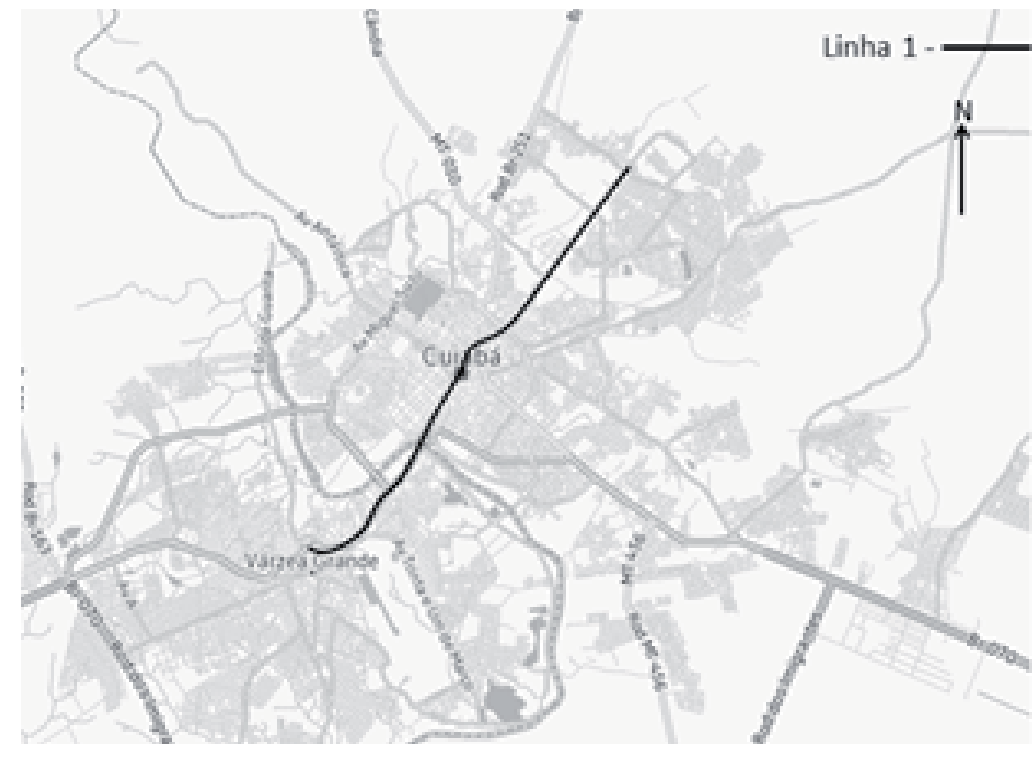

Figura 1 - Linha 1 do VLT no aglomerado urbano de Cuiabá e Várzea Grande, MT, Brasil

Fonte: Adaptado de Google Earth (2015).

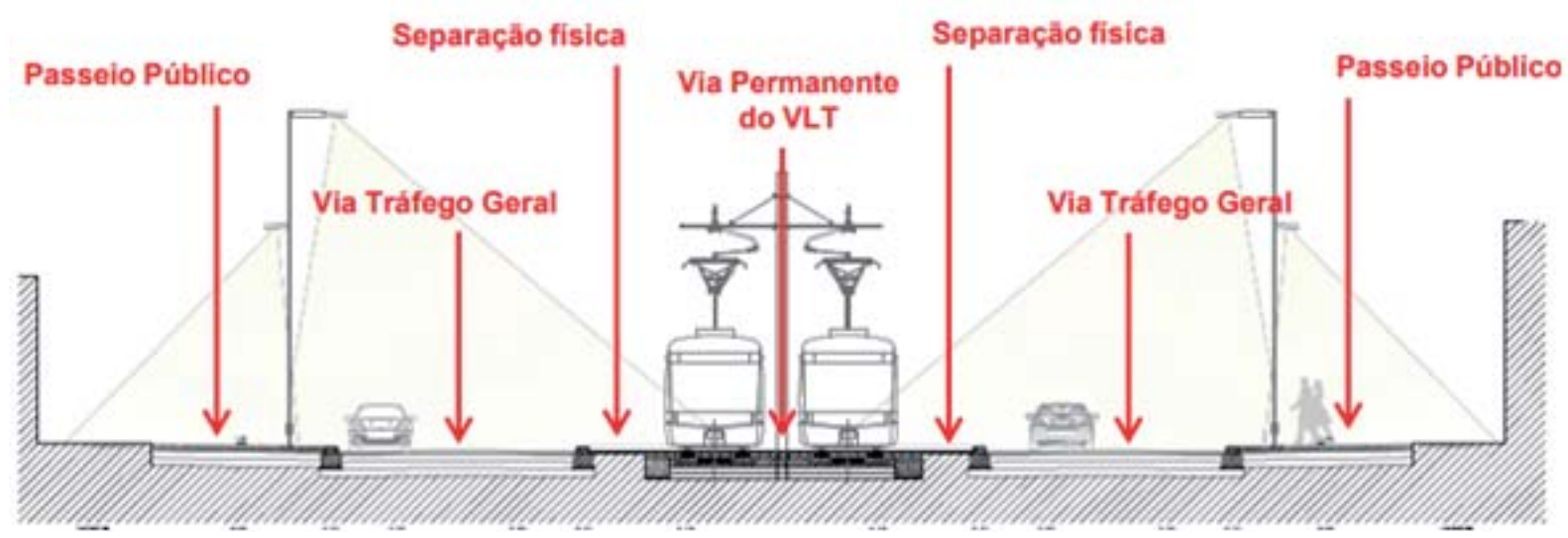

Figura 2 - Configuração viária após a intervenção para circulação do VLT na faixa central Fonte: MATO GROSSO (2012).

A metodologia apoiou-se nos pressupostos de Pinto, Guedes e Leite (2004). Em escala de análise urbana, foi realizado diagnóstico do ruído ambiental, do fluxo e da composição veicular do tráfego, no cenário atual, sem a presença do VLT. Em escala de análise de quadras, foram elaborados mapas acústicos para fins de validação dos modelos e para fins de simulação dos cenários acústicos devido ao acréscimo do modal VLT, em uma condição hipotética de operação, com retirada de $30 \%$ dos veículos leves e a totalidade dos ônibus de transporte coletivo. 


\subsection{Diagnóstico do ruído ambiental}

Realizou-se diagnóstico do ruído ambiental, antes da ocorrência das intervenções para implementação do VLT em 14 pontos georreferenciados (Tabela 1), com a realização de medições dos NPS e de contagem do volume de tráfego, simultaneamente em ambos os lados da via, sendo denominados "A" e "B", os sentidos Cuiabá-Várzea Grande e Várzea Grande-Cuiabá, respectivamente. Todos os pontos de medição possuem proximidade de atividades comerciais e de paradas de ônibus, com características de região urbana diversificada, sendo determinados em função da melhor segurança ofertada à equipe de campo durante a medição. Nos pontos 3 , 4 e 5, o sentido do tráfego é único, com 3 pistas de rolamento. No restante dos pontos, o sentido do tráfego é em mão dupla, com 2 pistas de rolamento simétricas ao canteiro central nos Pontos 1,2 e 3 e 3 pistas de rolamento nos demais.

Tabela 1 - Coordenadas geográficas e altitude dos pontos de medição, nos sentidos de tráfego da via de Cuiabá para Várzea Grande (A) e de Várzea Grande para Cuiabá (B)

\begin{tabular}{|c|c|c|c|c|c|c|c|}
\hline \multirow{2}{*}{ Pontos } & \multicolumn{2}{|c|}{ Coordenadas geográficas } & \multirow{2}{*}{$\begin{array}{l}\text { Altitude } \\
\text { (m) }\end{array}$} & \multirow{2}{*}{ Pontos } & \multicolumn{2}{|c|}{ Coordenadas geográficas } & \multirow{2}{*}{$\begin{array}{l}\text { Altitude } \\
(\mathrm{m})\end{array}$} \\
\hline & Latitude (S) & Longitude (W) & & & Latitude (S) & Longitude (W) & \\
\hline $1 \mathrm{~A}$ & $15^{\circ} 37^{\prime} 29,5^{\prime \prime}$ & $56^{\circ} 06^{\prime} 38,9^{\prime \prime}$ & 162 & $1 \mathrm{~B}$ & $15^{\circ} 37^{\prime} 29,2^{\prime \prime}$ & $56^{\circ} 06^{\prime} 39,4^{\prime \prime}$ & 163 \\
\hline $2 \mathrm{~A}$ & $15^{\circ} 37^{\prime} 08,6^{\prime \prime}$ & $56^{\circ} 06^{\prime} 23,68^{\prime \prime}$ & 157 & $2 B$ & $15^{\circ} 37^{\prime} 08,3^{\prime \prime}$ & $56^{\circ} 06^{\prime} 24,33^{\prime \prime}$ & 157 \\
\hline $3 A$ & $15^{\circ} 36^{\prime} 47,5^{\prime \prime}$ & $56^{\circ} 06^{\prime} 14,1^{\prime \prime}$ & 162 & $3 B$ & $15^{\circ} 36^{\prime} 47,0^{\prime \prime}$ & $56^{\circ} 06^{\prime} 14,6^{\prime \prime}$ & 162 \\
\hline $4 \mathrm{~A}$ & $15^{\circ} 36^{\prime} 39,1^{\prime \prime}$ & $56^{\circ} 06^{\prime} 11,8^{\prime \prime}$ & 170 & $4 B$ & $15^{\circ} 36^{\prime} 39,5^{\prime \prime}$ & $56^{\circ} 06^{\prime} 10,9^{\prime \prime}$ & 170 \\
\hline $5 \mathrm{~A}$ & $15^{\circ} 36^{\prime} 28,0^{\prime \prime}$ & $56^{\circ} 06^{\prime} 01,7^{\prime \prime}$ & 167 & $5 B$ & $15^{\circ} 36^{\prime} 28,3^{\prime \prime}$ & $56^{\circ} 06^{\prime} 01,5^{\prime \prime}$ & 167 \\
\hline $6 \mathrm{~A}$ & $15^{\circ} 36^{\prime} 14,7^{\prime \prime}$ & $56^{\circ} 05^{\prime} 57,0^{\prime \prime}$ & 167 & $6 B$ & $15^{\circ} 36^{\prime} 15,8^{\prime \prime}$ & $56^{\circ} 05^{\prime} 56,8^{\prime \prime}$ & 167 \\
\hline $7 \mathrm{~A}$ & $15^{\circ} 36^{\prime} 00,40^{\prime \prime}$ & $56^{\circ} 05^{\prime} 45,92^{\prime \prime}$ & 174 & $7 \mathrm{~B}$ & $15^{\circ} 36^{\prime} 00,92^{\prime \prime}$ & $56^{\circ} 05^{\prime} 45,38^{\prime \prime}$ & 173 \\
\hline $8 \mathrm{~A}$ & $15^{\circ} 35^{\prime} 51,5^{\prime \prime}$ & $56^{\circ} 05^{\prime} 37,1^{\prime \prime}$ & 176 & $8 B$ & $15^{\circ} 35^{\prime} 51,9^{\prime \prime}$ & $56^{\circ} 05^{\prime} 36,2^{\prime \prime}$ & 176 \\
\hline $9 \mathrm{~A}$ & $15^{\circ} 35^{\prime} 27,50^{\prime \prime}$ & $56^{\circ} 05^{\prime} 21,83^{\prime \prime}$ & 185 & $9 B$ & $15^{\circ} 35^{\prime} 27,8^{\prime \prime}$ & $56^{\circ} 05^{\prime} 20,97^{\prime \prime}$ & 185 \\
\hline $10 \mathrm{~A}$ & $15^{\circ} 35^{\prime} 19,45^{\prime \prime}$ & $56^{\circ} 05^{\prime} 03,44^{\prime \prime}$ & 211 & $10 B$ & $15^{\circ} 35^{\prime} 20,89^{\prime \prime}$ & $56^{\circ} 05^{\prime} 02,42^{\prime \prime}$ & 212 \\
\hline $11 \mathrm{~A}$ & $15^{\circ} 35^{\prime} 10,9^{\prime \prime}$ & $56^{\circ} 04^{\prime} 54,81^{\prime \prime}$ & 216 & 11B & $15^{\circ} 35^{\prime} 11,96^{\prime \prime}$ & $56^{\circ} 04^{\prime} 53,62^{\prime \prime}$ & 216 \\
\hline $12 \mathrm{~A}$ & $15^{\circ} 34^{\prime} 09,20^{\prime \prime}$ & $56^{\circ} 04^{\prime} 09,52^{\prime \prime}$ & 220 & $12 B$ & $15^{\circ} 34^{\prime} 09,70^{\prime \prime}$ & $56^{\circ} 04^{\prime} 08,21^{\prime \prime}$ & 219 \\
\hline $13 \mathrm{~A}$ & $15^{\circ} 33^{\prime} 42,76^{\prime \prime}$ & $56^{\circ} 03^{\prime} 48,70^{\prime \prime}$ & 238 & $13 \mathrm{~B}$ & $15^{\circ} 33^{\prime} 43,25^{\prime \prime}$ & $56^{\circ} 03^{\prime} 47,09^{\prime \prime}$ & 239 \\
\hline $14 \mathrm{~A}$ & $15^{\circ} 33^{\prime} 17,96^{\prime \prime}$ & $56^{\circ} 03^{\prime} 29,47^{\prime \prime}$ & 234 & $14 \mathrm{~B}$ & $15^{\circ} 33^{\prime} 18,65^{\prime \prime}$ & $56^{\circ} 03^{\prime} 28,38^{\prime \prime}$ & 236 \\
\hline
\end{tabular}

As medições de ruído ocorreram no período de junho de 2013 a outubro de 2014, das 7 às $9 \mathrm{~h}$ e das 17 às 19h, definidos para registrar os horários de maior tráfego veicular no trecho e, logo, de maior emissão de ruído, sendo representativos das condições sonoras ambientais mais desfavoráveis, conforme recomenda Miranda (2009). Em cada ponto, totalizaram-se 720 medições, conforme procedimentos da NBR 10151 (ABNT, 2000).

Foram utilizados os medidores de nível de pressão sonora Classe 1, modelos MSL1325 (Minipa) e DEC430 (Instrutherm), devidamente calibrados entre si em laboratório. Os dados foram compilados em planilhas eletrônicas para cálculo dos descritores sonoros $L_{e q^{\prime}} L_{10}$ e $L_{90}$ (ABNT, 1995; ABNT, 2000; SÃO PAULO, 1990; 1992), para cada ponto de medição. O nível $L_{e c}$ representa, em um intervalo de registro, o nível sonoro estacionário que gera a mesma energia sonora produzida pelos eventos sonoros registrados. O nível estatístico $L_{10}$ é aceito como valores de pico em estudos de ruído, pois indica valores que foram excedidos em apenas $10 \%$ do tempo total de medição. Já o nível estatístico $L_{90}$ é aceito como o ruído de fundo, posto que indica o nível que foi ultrapassado durante 90\% do tempo de medição (SÃO PAULO, 1992; BISTAFA, 2006). 
A contagem do tráfego foi feita em cada ponto de medição e nos dois sentidos de tráfego, com registro manual do fluxo e da composição do tráfego veicular (número de veículo por tipo: carro, moto, ônibus, caminhão, outros).

Para determinação de um único valor de ruído e da quantidade de veículos em cada ponto, considerou-se a média dos níveis de pressão sonora equivalente e da contagem de tráfego (em veículos/hora) nos dois sentidos de tráfego.

Condições urbanas com potencial de impacto na poluição sonora devem ser analisadas à luz do Nível Critério de Avaliação (NCA), definido pela NBR 10151 (ABNT, 2000) como o nível de ruído máximo recomendado para o ambiente externo, de acordo com o período do dia e o tipo da área urbana. Para área mista, com vocação comercial e administrativa tal qual a da pesquisa, os limites diurno e noturno (das 22 às 7 h) são de 60 e $55 \mathrm{~dB}(\mathrm{~A})$ ), respectivamente. No Estado de Mato Grosso, a Lei Municipal 3.819 (CUIABÁ, 1999) estabelece os limites de acordo com o zoneamento urbano, em condições de medições da NBR 10151 (ABNT, 2000), definindo como período diurno, vespertino e noturno aqueles compreendidos entre 7 e 19h, 19 e $22 \mathrm{~h}$ e 22 e 7h, respectivamente. Para a zona diversificada, os limites matutino, vespertino e noturno são de 65, 60 e 55dB(A), respectivamente, sendo, portanto, mais permissivos das 7 às $19 \mathrm{~h}$ que a normativa nacional. Constada essa divergência, adotaram-se os limites da ABNT 10151 (2000).

\subsection{Simulação de cenários}

Uma vez que o modal VLT ainda está em fase de implementação, utilizou-se simulação computacional em uma abordagem por cenários, que foram modelados agrupando-se as quadras em torno dos pontos de medição, considerando-se uma área de 120x120m. Os Pontos 1 e 2 foram modelados agrupados em uma única área, assim como os pontos 3, 4 e 5. Os demais pontos não foram agrupados para modelagem e sempre foram consideradas as edificações e topografia existentes, levantadas in loco e com auxílio de imagens de satélite.

Nos cenários foram adicionadas as linhas de tráfego correspondentes ao eixo estrutural viário do local e ao eixo do modal VLT, com o ponto de medição no centro e com velocidade de operação prevista para o VLT de 60 a 80km/h (MATO GROSSO, 2012).

Os modelos foram validados conforme Pinto, Guedes e Leite (2004), elaborando-se mapas acústicos tomando-se o NPS em receptores localizados em posição idêntica à dos pontos de medição e com os dados de contagem volumétrica de tráfego de cada ponto. A simulação foi aceita nos casos em que a diferença entre os valores simulados e medidos foi inferior a $\pm 3 \mathrm{~dB}(\mathrm{~A})$. Desvios superiores implicariam novas medições e novas simulações e, portanto, foram descartados. Registra-se que Garavelli et al. (2013) bem como Silva (2015) admitiram o erro máximo de $\pm 3 \mathrm{~dB}(\mathrm{~A})$ para validação dos mapas acústicos, e a European Commission Working Group Assessment of Exposure to Noise (WG-AEN, 2007) admitiu variações de até 4,6dB(A). Dessa forma, considerando a similaridade dos valores medidos e simulados, admite-se que o modelo de simulação pode ser utilizado para avaliação de situações que não as medidas, como forma de predição do ruído em cenários futuros resultantes de intervenções urbanas.

Os mapas acústicos foram gerados no SoundPlan ${ }^{\circledR} 7.3 \mathrm{com}$ base no plano horizontal (Grid Noise Map). No Cenário 1, tomou-se o tráfego conforme a contagem volumétrica das medições. No Cenário 2, o VLT foi adicionado, os veículos leves foram reduzidos de $30 \%$ e retirados de circulação todos os ônibus de transporte coletivo, conforme previsto no Anteprojeto do Veículo Leve Sobre Trilhos (MATO GROSSO, 2012 ). Em ambos os cenários, a velocidade dos veículos adotada foi a de $60 \mathrm{~km} / \mathrm{h}$, atual limite na via. 
Também foram simulados cenários referentes a outras possibilidades de operação dos modais no corredor estrutural. O Cenário 3 corresponde à previsão de não ocorrer redução do número de veículos leves após a implementação do VLT, apenas a retirada de todos os ônibus. Os Cenários 4 e 5 correspondem à redução de $50 \%$ da frota dos veículos leves e pesados, com velocidades de tráfego de 60 e $40 \mathrm{~km} / \mathrm{h}$, respectivamente, justificados pela possibilidade de operacionalização sem a retirada da totalidade dos ônibus do corredor estrutural.

\section{RESULTADOS}

\subsection{Diagnóstico do ruído ambiental}

O ruído equivalente $\left(L_{e q}\right)$ foram $79 \mathrm{~dB}(A)$ nos Pontos 1 e 2; 78 e $77 \mathrm{~dB}(A)$ nos Pontos 6 e 5; $76 \mathrm{~dB}(\mathrm{~A})$ nos Pontos 4 e 9; 74dB(A) nos Pontos 8 e 10 e $75 \mathrm{~dB}(\mathrm{~A})$ nos demais pontos. Os Pontos 5 e 8 , cujos Leq são iguais a 63 e $65 \mathrm{~dB}(\mathrm{~A})$, respectivamente, adequados ao limite de $65 \mathrm{~dB}(\mathrm{~A})$ estipulado pela Lei Municipal n. 3819 (CUIABÁ, 1999), porém extrapolam os limites da NBR 10151 (ABNT, 2000). Nos demais pontos, até mesmo o ruído de fundo $\left(L_{90}\right)$ se encontra acima desses limites. O ruído de pico $\left(\mathrm{L}_{10}\right)$ ultrapassou $75 \mathrm{~dB}(\mathrm{~A})$ em todos os pontos (Tabela 2, Figura 3 ).

Os resultados evidenciam que os níveis de ruído equivalente $\left(L_{e q}\right)$ excedem o limite legal de $65 \mathrm{~dB}(\mathrm{~A})$, sendo este já superado pelo ruído de fundo $\left(L_{90}\right)$, o que não permite o enquadramento ao limite legal sem incluir o ruído como um condicionante ambiental do planejamento urbano, destacando a importância de estudos que relacionem a forma urbana e a espacialização sonora.

Assim como neste estudo, Pinto (2013) e Bressane et al. (2016), diagnosticaram o ruído ambiental urbano e constataram que os níveis medidos se encontravam acima dos recomendados pela normativa brasileira. Destaca-se que, conforme Gerges (2000), quando os limites são superados em cerca de $10 \mathrm{~dB}(\mathrm{~A})$, a reação esperada da comunidade é de que surjam queixas da população e, quando os limites são superados em mais de $15 \mathrm{~dB}(\mathrm{~A})$, podem causar respostas mais enérgicas, como ações comunitárias.

Tabela 2 - Ruído ambiental, contagem do tráfego e ruído simulado nos Cenários 1 e 2

\begin{tabular}{c|c|c|c|c|c|c|c}
\hline \multirow{2}{*}{ Pontos } & \multicolumn{5}{|c|}{ Diagnóstico } & \multicolumn{2}{c}{ Simulação } \\
\cline { 2 - 8 } & $\begin{array}{c}\mathbf{L}_{\text {eq }} \\
\mathbf{d B}(\mathbf{A})\end{array}$ & $\begin{array}{c}\mathbf{L}_{10} \\
\mathbf{d B}(\mathbf{A})\end{array}$ & $\begin{array}{c}\mathbf{L}_{90} \\
\mathbf{d B}(\mathbf{A})\end{array}$ & $\begin{array}{c}\text { Veículos } \\
\text { leves/hora }\end{array}$ & $\begin{array}{c}\text { Veículos } \\
\text { pesados (\%) }\end{array}$ & $\begin{array}{c}\text { Cenário 1 } \\
\mathbf{d B}(\mathbf{A})\end{array}$ & $\begin{array}{c}\mathbf{L}_{\text {eq }} \text {-Cenário1 } \\
\mathbf{d B}(\mathbf{A})\end{array}$ \\
\hline 1 & 78,67 & 82,07 & 71,15 & 1673 & 5,68 & 76,05 & 2,62 \\
\hline 2 & 78,87 & 82,52 & 71,32 & 1871 & 5,50 & 77,55 & 1,32 \\
\hline 3 & 74,68 & 78,7 & 66,03 & 2456 & 5,30 & 76,30 & $-1,62$ \\
\hline 4 & 75,81 & 79,55 & 67,57 & 2251 & 4,80 & 74,00 & 1,81 \\
\hline 5 & 76,86 & 80,61 & 62,60 & 2576 & 5,35 & 76,40 & 0,46 \\
\hline 6 & 78,14 & 81,9 & 70,14 & 960 & 6,60 & 73,10 & 5,04 \\
\hline 7 & 74,64 & 78,03 & 67,34 & 2044 & 8,05 & 77,65 & $-3,01$ \\
\hline 8 & 74,48 & 78,18 & 65,34 & 1919 & 7,65 & 77,00 & $-2,52$ \\
\hline 9 & 76,45 & 80,24 & 69,27 & 2439 & 3,25 & 74,20 & 2,25 \\
\hline 10 & 73,92 & 77,22 & 67,43 & 1317 & 4,20 & 70,25 & 3,67 \\
\hline 11 & 75,12 & 78,28 & 69,06 & 2760 & 2,95 & 74,70 & 0,42 \\
\hline 12 & 75,16 & 79,29 & 65,56 & 1426 & 4,40 & 71,70 & 3,46 \\
\hline 13 & 74,89 & 78,76 & 66,37 & 1389 & 4,08 & 72,75 & 2,14 \\
\hline 14 & 75,02 & 79,23 & 66,54 & 920 & 3,78 & 70,20 & 4,80 \\
\hline
\end{tabular}




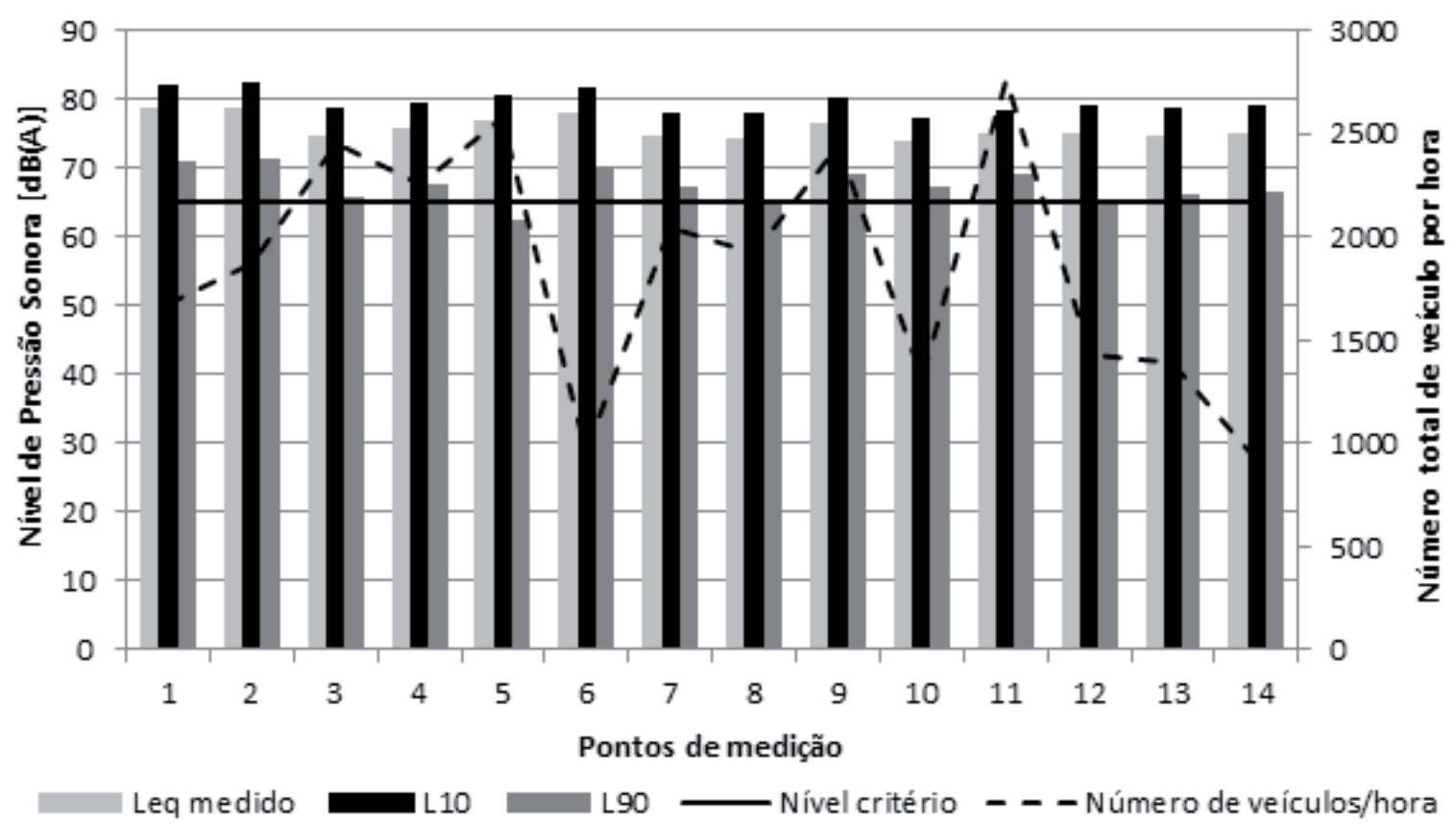

Figura 3 - Nível Critério, $L_{e q}, L_{10}, L_{90}$ e número total de veículos por hora considerando a média dos valores medidos nos pontos, nos dois sentidos da via e nos dois períodos de medição

Os pontos que apresentaram maiores valores de ruído foram os Pontos 2, 1, 6, 5, 4 e 12, $\operatorname{com} 78,87 \mathrm{~dB}(\mathrm{~A}), 78,67 \mathrm{~dB}(\mathrm{~A}), 78,14 \mathrm{~dB}(\mathrm{~A}), 76,86 \mathrm{~dB}(\mathrm{~A}), 75,81 \mathrm{~dB}(\mathrm{~A})$ e $75,16 \mathrm{~dB}(\mathrm{~A})$, respectivamente. No entanto esses não foram os pontos que registraram o maior volume de tráfego de veículos por hora, o que ocorreu nos pontos 11, 5, 3, 9, 7, 4 e 8 com 2760, 2576, 2456, 2439, 2251, 2044, 1919 veículos/hora, respectivamente (Tabela 2, Figura 3). Não foi possível estabelecer uma relação entre $o L_{e q}$ e o tráfego uma vez que as medições foram realizadas somente em horários de pico e somente em condição de tráfego intenso.

A menor variabilidade foi obtida no Ponto 11 , no valor de $9 \mathrm{~dB}(\mathrm{~A})$. Nos demais pontos, a variabilidade teve amplitude sempre maior que $10 \mathrm{~dB}(\mathrm{~A})$, chegando a $18 \mathrm{~dB}(\mathrm{~A})$ no Ponto 5 . A variabilidade caracteriza a presença do tráfego como determinante do ruído ambiental, ocasionada pelas acelerações, frenagens e diversidade de veículos que trafegam no local.

\subsection{Simulação de cenários}

A partir dos mapas acústicos do Cenário 1, com o tráfego medido em campo, foi obtida a diferença entre os dados medidos e simulados, que foi menor que $\pm 3 \mathrm{~dB}(\mathrm{~A})$ nos Pontos $1,2,3,4$, $5,8,9,11$ e 13, considerados validados para elaboração dos mapas acústicos do Cenário 2. Pinto (2013) admitiu a variação de 4,6dB(A) em sua calibração, admitindo, portanto, maior variação entre os dados medidos e simulados em relação ao presente estudo.

No Cenário 2, no qual o VLT foi adicionado, os veículos leves foram reduzidos de $30 \%$ e retirados de circulação todos os ônibus de transporte coletivo (Tabela 3). Nos Pontos 1, 2, 3, 4, 9, 11 e 13 ocorreu redução de até $2 \mathrm{~dB}(\mathrm{~A})$ e nos Pontos 5 e 8, entre 2 e 2,50dB(A), do Cenário 2 em

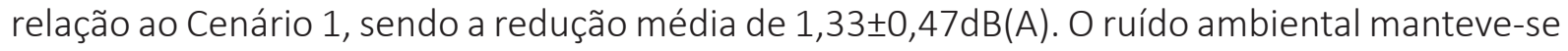
acima do nível critério de $65 \mathrm{~dB}(\mathrm{~A})$. O impacto da implementação do VLT no cenário da cidade de Cuiabá, MT, foi semelhante ao avaliado para a cidade de Brasília por Maroja et al. (2013), que identificou redução de até $2 \mathrm{~dB}(\mathrm{~A})$. 
Nos mapas acústicos, observa-se que onde não existem edificações lindeiras à via, houve redução do ruído próximo às bordas da área simulada de $4 \mathrm{~dB}(\mathrm{~A})$, o que corresponde à mudança de categoria na escala de avaliação de 52-56 para 48-52 dB(A) (conforme indicado pelas setas nas Figuras 4 e 5). Isso ocorre porque os vazios urbanos facilitam a propagação do ruído para as áreas mais afastadas da via, permitindo que o som se propague com menor interferência dos obstáculos por maiores distâncias de seu eixo, local das fontes sonoras. Como evidência, tem-se, na parte central da Figura 4, a existência de um vazio urbano lindeiro à via, no sentido CuiabáVárzea Grande (Figura 6), em que o som se propaga em campo livre, uma vez que o terreno é nivelado e sem barreiras. Também ocorreu redução do ruído nas proximidades da via do VLT, que passa das categorias de "maior que $80 \mathrm{~dB}(A)$ " para "76 a $80 \mathrm{~dB}(\mathrm{~A})$ " e de "72 a $76 \mathrm{~dB}(\mathrm{~A})$ " para "68 a $72 \mathrm{~dB}(\mathrm{~A})$ ".

Tabela 3 - Ruído ambiental nos cenários validados

\begin{tabular}{|c|c|c|c|c|}
\hline Pontos & $\begin{array}{c}\text { Cenário } 2^{1} \\
\mathrm{~dB}(\mathrm{~A})\end{array}$ & $\begin{array}{c}\text { Cenário } 3^{2} \\
\mathrm{~dB}(\mathrm{~A})\end{array}$ & $\begin{array}{c}\text { Cenário } 4^{3} \\
\mathrm{~dB}(\mathrm{~A})\end{array}$ & $\begin{array}{c}\text { Cenário } 5^{4} \\
\mathrm{~dB}(\mathrm{~A})\end{array}$ \\
\hline 1 & 75,25 & 75,45 & 72,90 & 71,65 \\
\hline 2 & 76,15 & 76,45 & 74,50 & 73,25 \\
\hline 3 & 75,35 & 76,20 & 73,85 & 72,70 \\
\hline 4 & 72,65 & 73,65 & 71,40 & 70,15 \\
\hline 5 & 74,30 & 75,40 & 73,10 & 71,70 \\
\hline 9 & 75,10 & 74,30 & 72,10 & 70,80 \\
\hline 11 & 75,05 & 74,20 & 71,60 & 69,90 \\
\hline $\begin{array}{c}\text { Redução média em relação Cenário } 1 \\
\pm \text { desvio padrão }[\mathrm{dB}(\mathrm{A})]\end{array}$ & $1,33 \pm 0,47$ & $0,51 \pm 0,44$ & $2,82 \pm 0,44$ & $4,15 \pm 0,54$ \\
\hline
\end{tabular}

1: redução de $30 \%$ dos veículos leves, $100 \%$ dos veículos pesados, $v=60 \mathrm{~km} / \mathrm{h}$. $2:$ sem redução de veículos leves, redução de $100 \%$ dos veículos pesados, $v=60 \mathrm{~km} / \mathrm{h}$. 3: redução de $50 \%$ dos veículos leves e pesados, $v=60 \mathrm{~km} / \mathrm{h}$. 4: redução de $50 \%$ dos veículos leves e pesados, $v=40 \mathrm{~km} / \mathrm{h}$

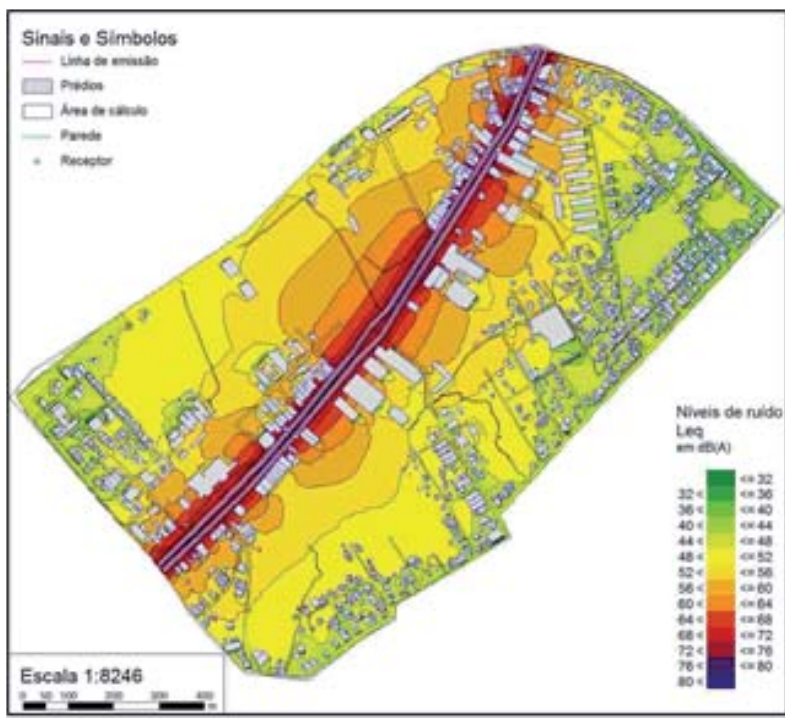

a)

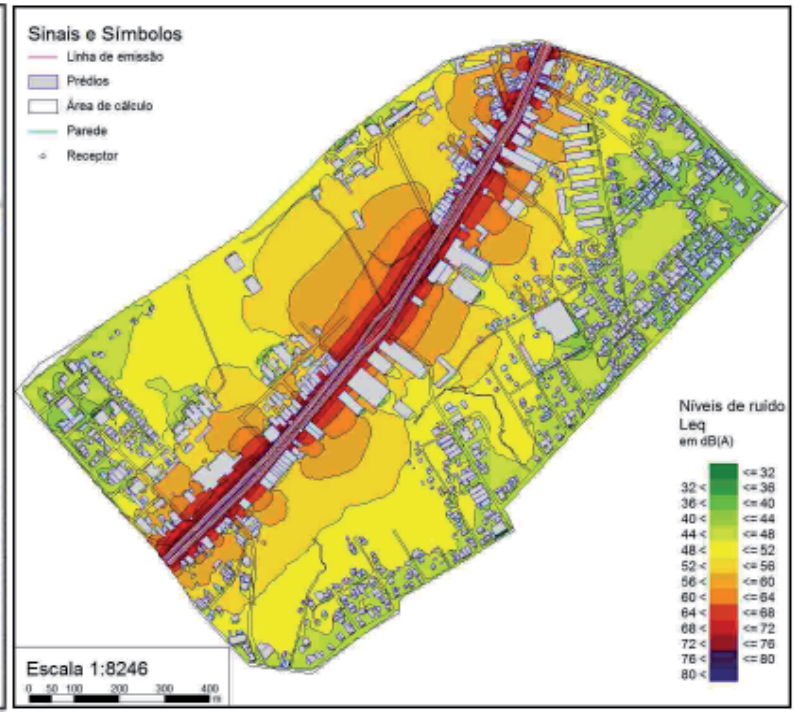

b)

Figura 4 - Mapa acústico dos Pontos 1 e 2 no Cenário 1(a) e no Cenário 2 (b) 


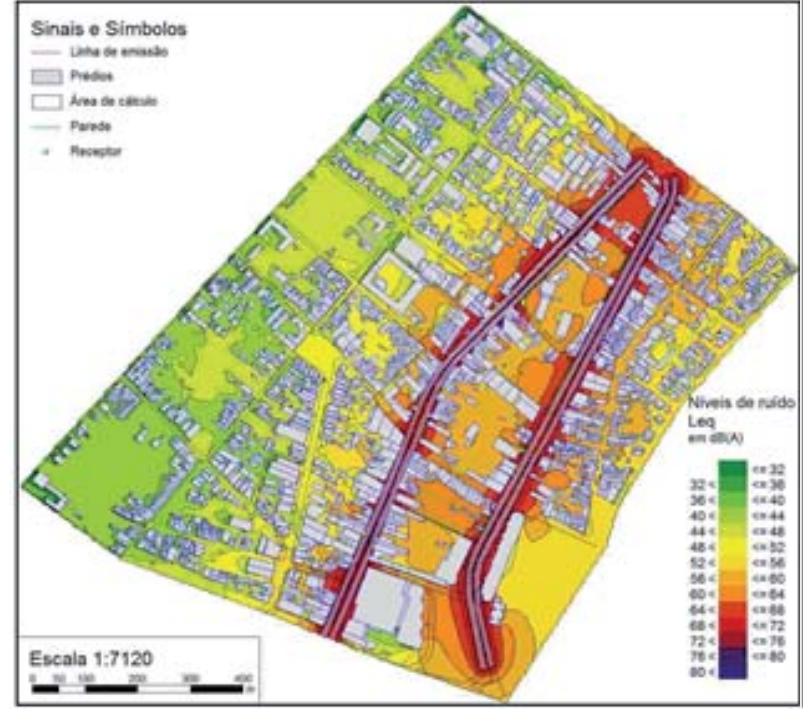

a)

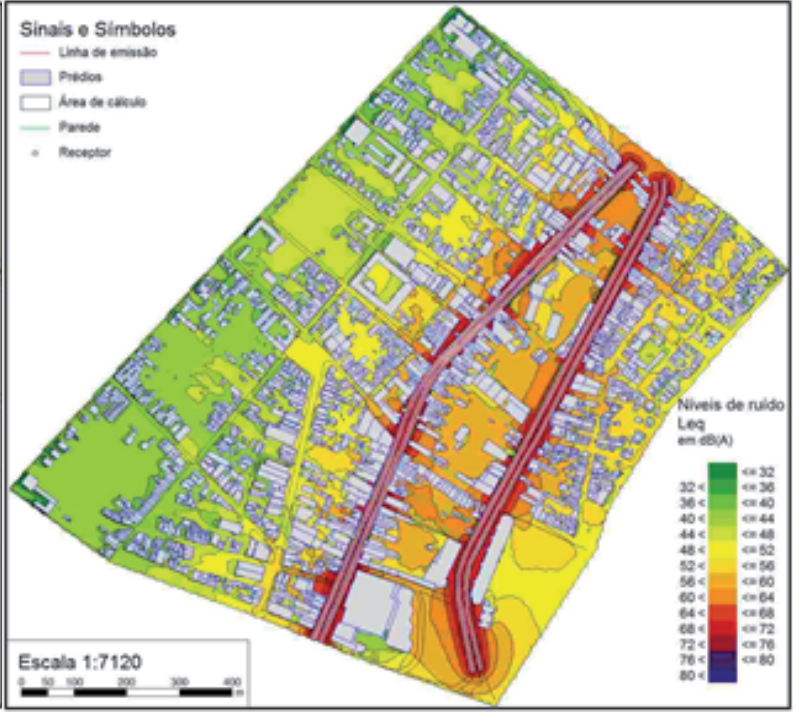

b)

Figura 5 - Mapa acústico dos Pontos 3, 4 e 5 no Cenário 1(a) e no Cenário 2 (b)

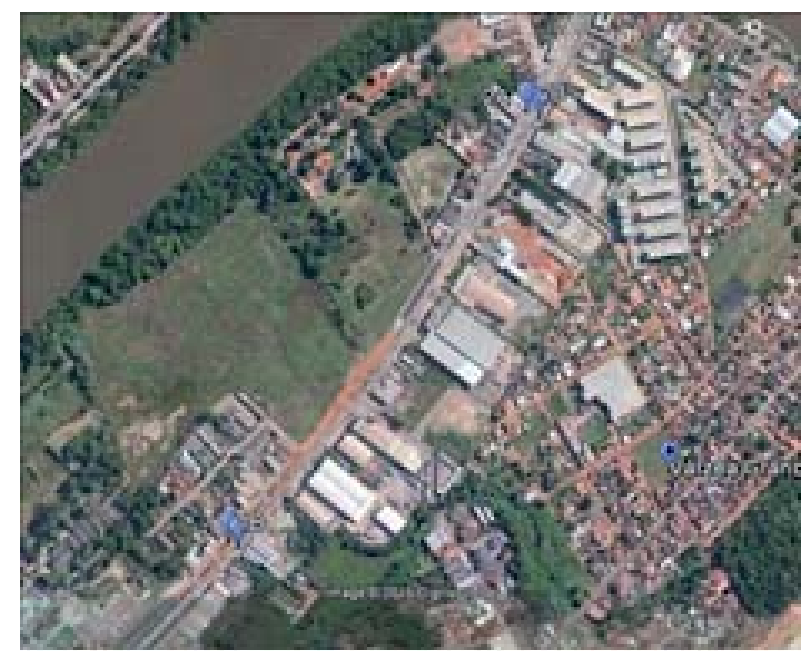

Figura 6 - Detalhe do vazio urbano, na parte central do mapa dos Pontos 1 e 2

Fonte: Adaptado de Google Earth (2015).

Nos receptores dos Pontos 8, 9 e 11, o decréscimo do ruído do Cenário 2 em relação ao Cenário 1 foi de 2,50dB(A), 0,95dB(A) e 1,75dB(A), respectivamente (Figuras 7, 8 e 9, respectivamente). Nos locais desses mapas onde se verificam características de canyon urbano, tal como indicado pelas setas nas Figuras 8 e 9, observa-se a concentração do ruído junto ao centro da via. Isso ocorre porque os edifícios atuam como barreira sonora, com capacidade de proteção que varia de acordo com suas características de forma, implantação e material, com o que corrobora Guedes (2005). Nesse sentido, destaca-se que o processo de adensamento e verticalização tem a capacidade de interferir na paisagem acústica e que o perfil da via define a contribuição do campo direto e refletido (devido ao tráfego e às fachadas, respectivamente), conclusão semeIhante com o estudo de Cortês e Niemeyer (2013). 


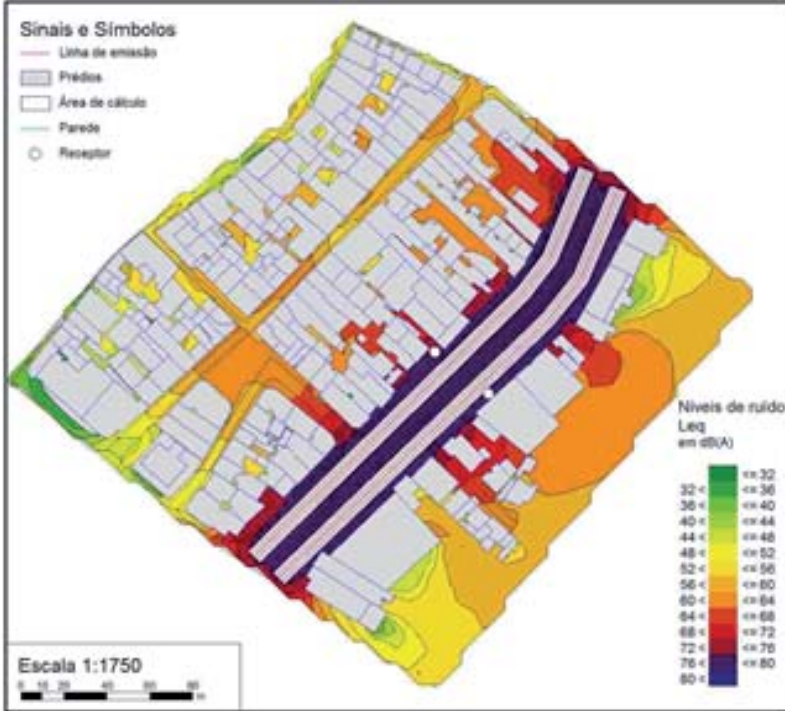

a)

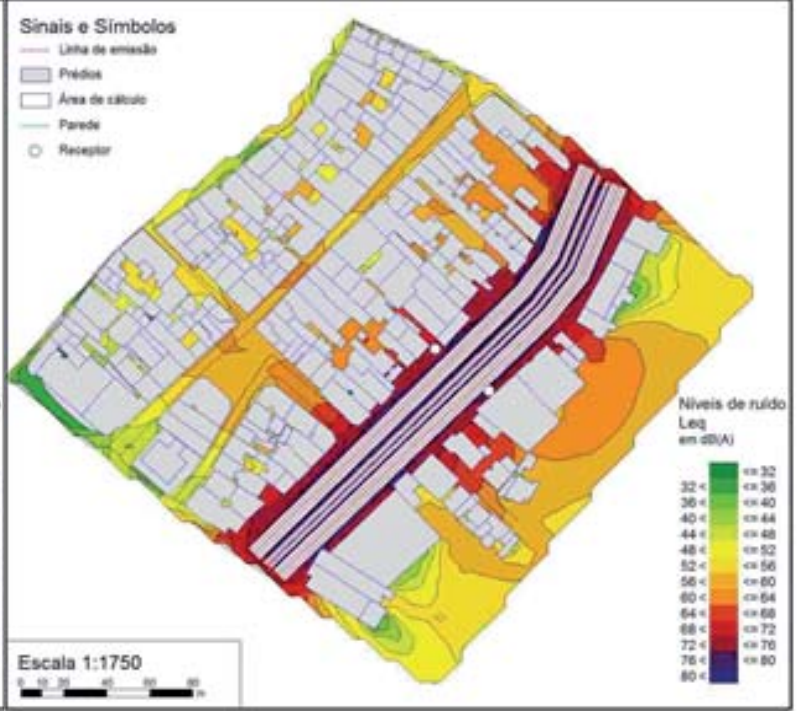

b)

Figura 7 - Mapa acústico do Ponto 8 no Cenário 1(a) e no Cenário 2 (b)

Evidenciando os impactos do Cenário 2 em relação ao Cenário 1, a intervenção proporciona decréscimo dos níveis sonoros no alinhamento das fachadas das edificações da via, a exemplo do que ocorre nas fachadas destacadas por círculos nas Figuras 8 e 9 e pela forma retangular na Figura 10, que corresponde a uma praça. Essas áreas têm seus níveis de ruído reduzidos de 4dB. Como o ruído é perceptível ao ouvido humano em variações sonoras de pelo menos $3 \mathrm{~dB}$, isso significa dizer que esse decréscimo será percebido pelas pessoas, que poderão declarar menor incômodo, caso o Cenário 2 se concretize, conforme previsão de percepção da comunidade proposta por Gerges (2000).

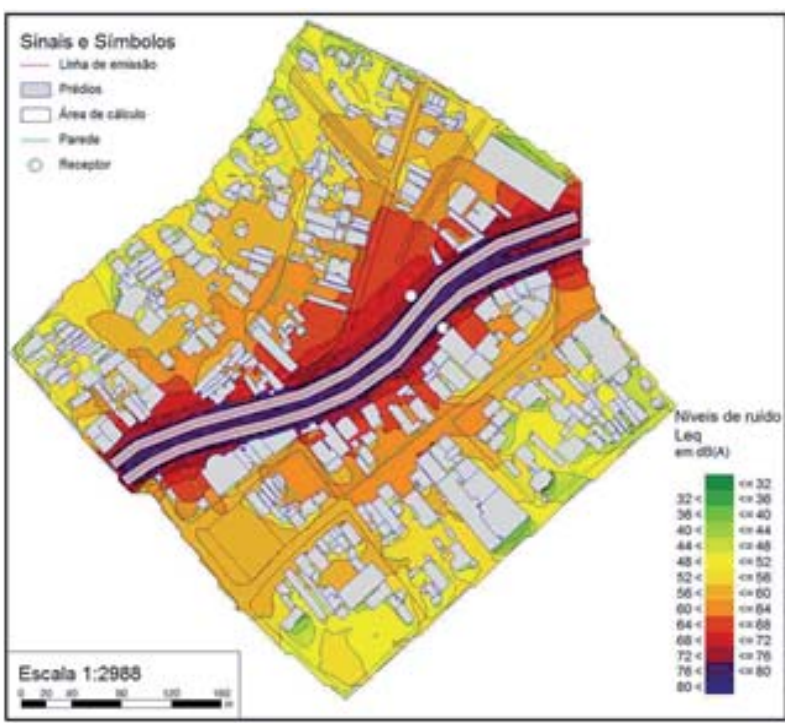

a)

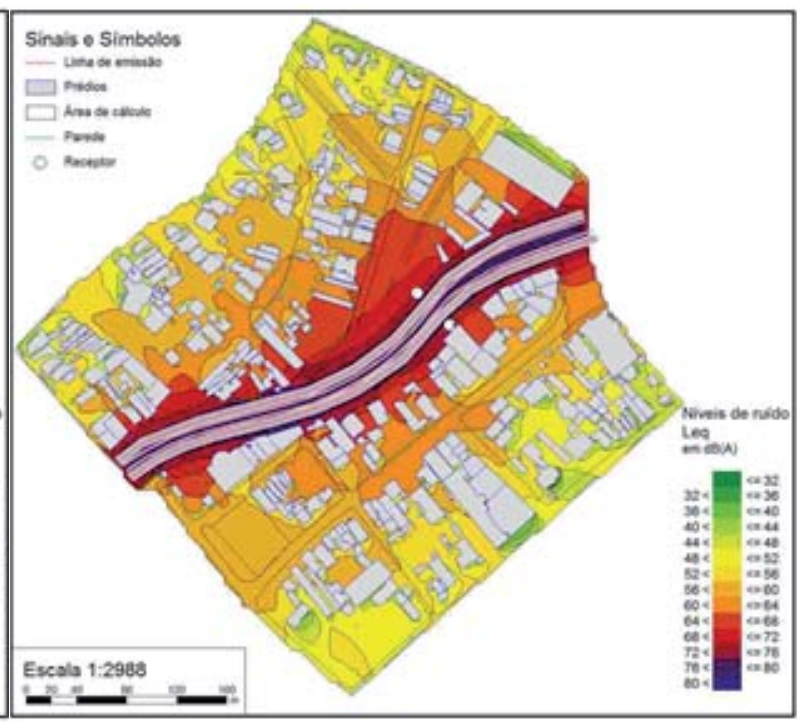

b)

Figura 8 - Mapa acústico do Ponto 9 no Cenário 1(a) e no Cenário 2 (b) 


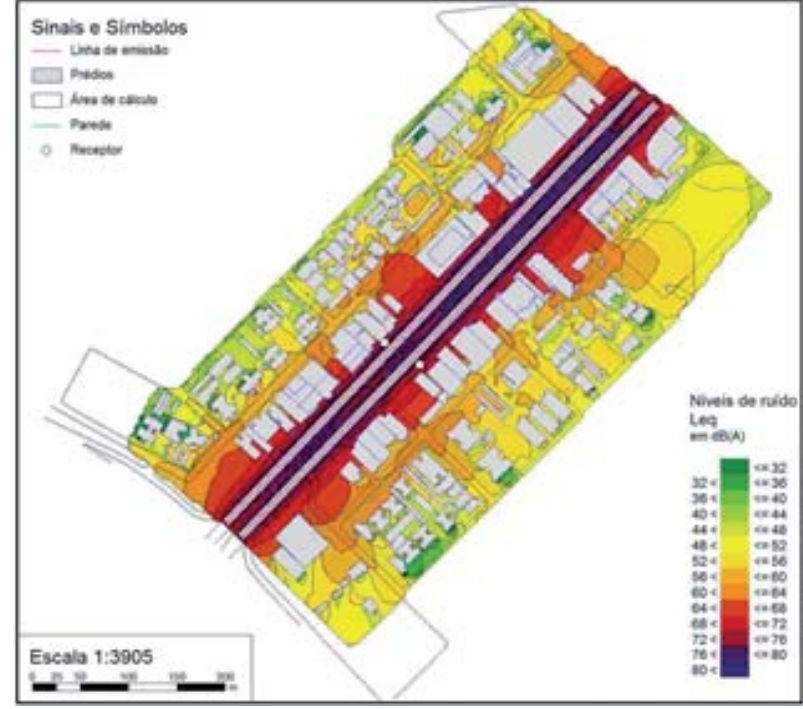

a)

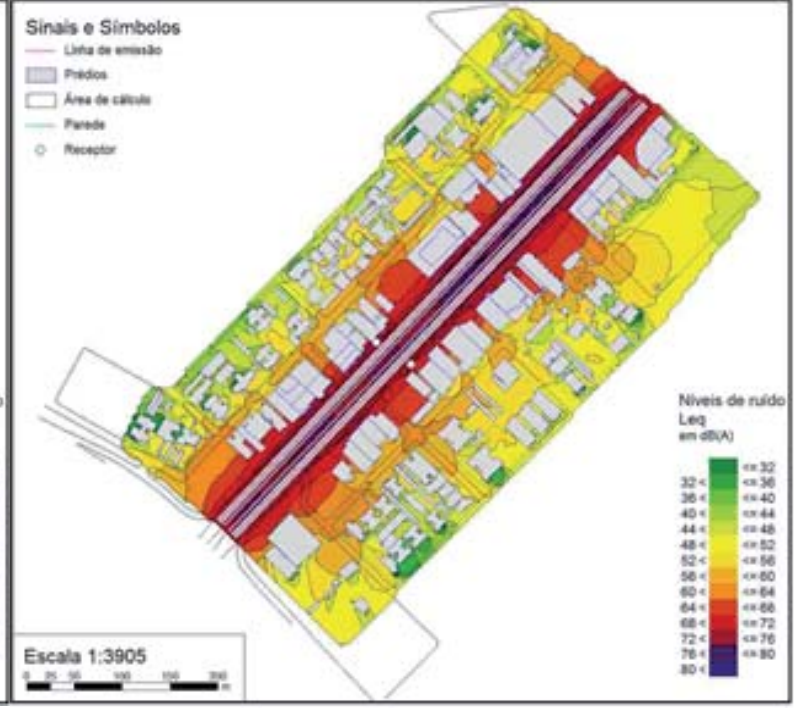

b)

Figura 9 - Mapa acústico do Ponto 11 no Cenário 1 (a) e no Cenário 2 (b)

Nas regiões de baixa densidade construtiva (Figura 10, correspondente ao Ponto 13), ocorreu o menor impacto entre os Cenários 1 e 2, com redução de 0,65dB(A).

Nesse mapa, a região destacada pela forma retangular na Figura 10, configuram-se os efeitos de barreira e sombra acústica, proporcionados pelas edificações isoladas, criando uma zona de menor pressão sonora na face oposta a estas. Cortês e Niemeyer (2014) exploraram as formas das edificações (retangular, em forma de " $\mathrm{L}$ ", circular e retangular com bandejas) e evidenciaram que a forma circular é a que menos protege o interior das quadras, permitindo maior propagação horizontal do ruído das vias para o interior dos lotes. A existência de bandeja nos primeiros pavimentos criou uma região de sombra acústica bastante eficiente, nos pavimentos inferiores, e o formato em "L" pode expor maior número de fachadas, dependendo da implantação. Em se tratando de fachadas retangulares, a fachada fixada no limite do recuo recebe maior poluição sonora e, quanto maior comprimento tiver, esse nível sonoro mais elevado se prolonga por toda a sua extensão.

Evidencia-se, dessa forma, a relação entre a espacialidade do ruído e o adensamento construtivo, o que indica a possibilidade de aplicação dos mapas de ruído para subsidiar decisões de projeto das edificações, tais como gabarito, implantação, especificação de materiais das fachadas e estudo da forma das edificações como meio de mitigação da propagação do ruído. 


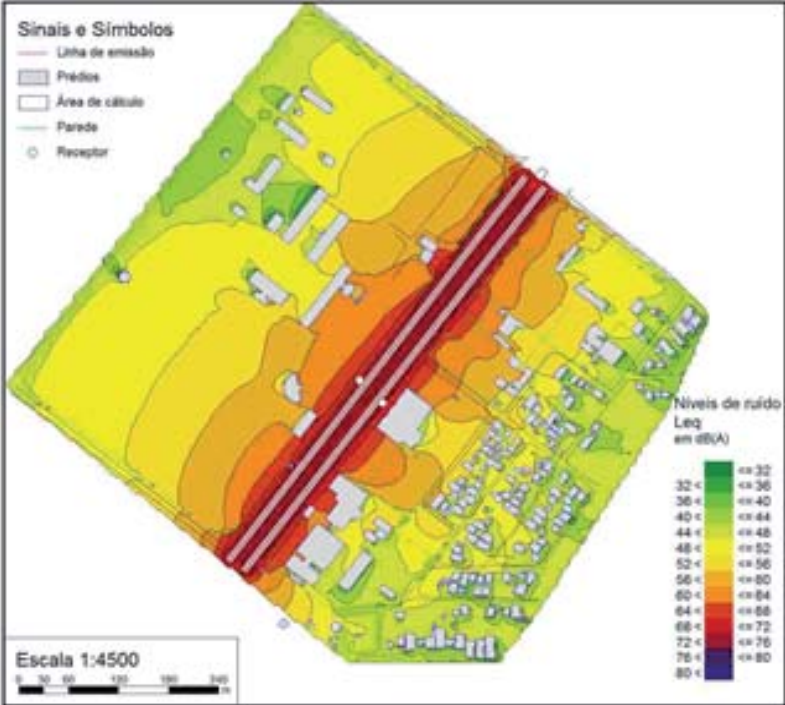

a)

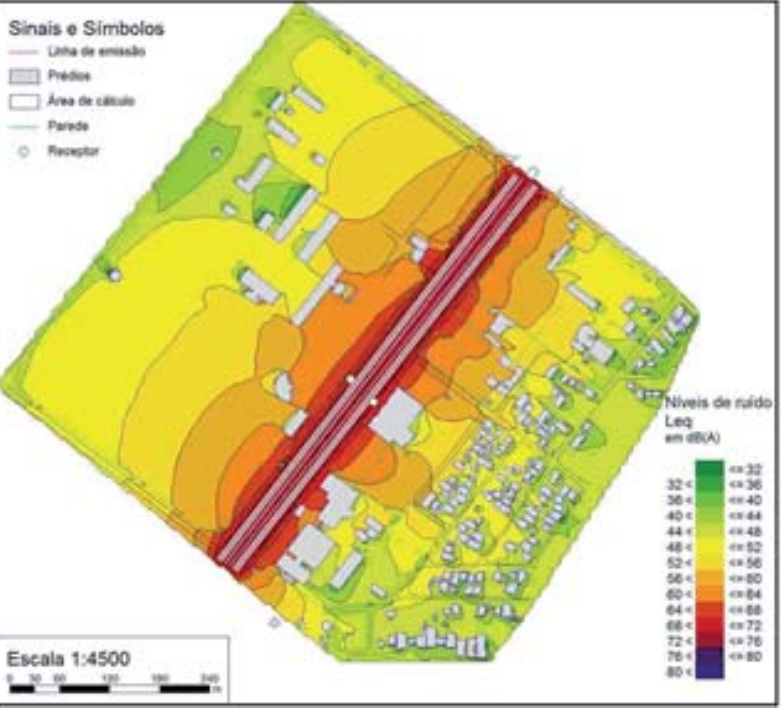

b)

Figura 10 - Mapa acústico dos Pontos 13 no Cenário 1(a) e no Cenário 2 (b)

Diante do baixo impacto no ruído ambiental da condição de operação do modal VLT proposta no Cenário 2, buscou-se a exploração de outras possibilidades hipotéticas de operação sempre comparadas em relação ao Cenário 1.

Nesse sentido, verificou-se no Cenário 3, no qual foi mantido o número de veículos leves correspondentes à frota atualmente em circulação no corredor estrutural, sem retirada dos veículos de transporte coletivo. Nesse cenário, os níveis de ruído sofreriam redução média de $0,51 \pm 0,44 \mathrm{~dB}(\mathrm{~A})$, sendo maior nos Pontos 2 e 5 (Tabela 3). No Cenário 4, que representa uma situação hipotética de retirada de $50 \%$ da frota circulante com velocidade de $60 \mathrm{~km} / \mathrm{hora}$, obteve-se redução média de 2,82 $\pm 0,44 \mathrm{~dB}(\mathrm{~A})$. Esses resultados confirmam que as principais fontes sonoras são os veículos automotores, tal como afirmado por Bressane et al. (2016). Este estudo acrescenta a essa constatação que os veículos pesados (ônibus coletivos) são os principais responsáveis pelos níveis sonoros urbanos, justificado pela elevada frequência de paradas, o que implica acelerações e frenagens durante o trajeto, aliado, muitas vezes, à baixa manutenção da frota e às próprias características dos motores, com elevada emissão sonora.

Já no Cenário 5, explorou-se a possibilidade de redução da velocidade de tráfego para $40 \mathrm{~km} / \mathrm{h}$, obtendo-se redução média de $4,15 \pm 0,54 \mathrm{~dB}(\mathrm{~A})$, que, no entanto, ainda não proporciona o seu enquadramento ao nível critério de $65 \mathrm{~dB}(\mathrm{~A})$ estabelecido pela legislação local. Os níveis de ruído resultantes nos pontos ainda ficaram de 4,9 a $8,25 \mathrm{~dB}(\mathrm{~A})$ maiores que o nível critério. Essa informação é importante, pois pode subsidiar ações de gerenciamento da mobilidade urbana e engenharia de tráfego. Por meio dessa abordagem, foi possível comprovar o proposto por Zannin e Sant'anna (2011), que indicam a necessidade de gerenciamento e controle da emissão sonora por meio de medidas administrativas, tais como: controle da emissão sonora e velocidade dos veículos, estímulo ao uso de transporte público e alternativas de modais e programas de monitoramento de ruído. 


\section{CONCLUSÃO}

O diagnóstico do ruído ambiental indicou que os níveis de pressão sonora no corredor estrutural viário analisado encontravam-se acima do nível critério de $65 \mathrm{~dB}(\mathrm{~A})$. O ruído de fundo ultrapassou o valor limite em 12 dos 14 pontos medidos, configurando situação de poluição sonora, carecendo de medidas de gestão pública integrada com vistas à minimização dos impactos decorrentes do atual modal de transporte e uso e ocupação do solo urbano.

No Cenário 2, representativo das condições em que os veículos leves foram reduzidos em $30 \%$ e retirados de circulação todos os ônibus de transporte coletivo, conforme previsto no

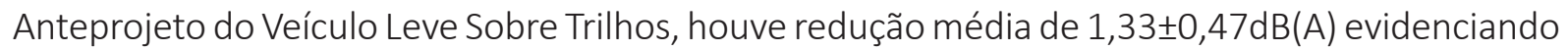
que a implementação do modal VLT contribui para minimização do ruído na região de maneira considerável, gerando ambientes de melhor qualidade ambiental. Observou-se, nos mapas acústicos, em áreas mais afastadas do eixo central da via, o decréscimo da ordem de $4 \mathrm{~dB}(\mathrm{~A})$. Como o ruído é perceptível ao ouvido humano em variações sonoras de pelo menos $3 \mathrm{~dB}$, isso significa dizer que esse decréscimo será percebido pelas pessoas, que poderão declarar menor incômodo, caso o Cenário 2 se concretize.

Com caráter complementar visando ao gerenciamento da mobilidade urbana, foi simulado o Cenário 3, no qual foram retirados de circulação do corredor viário apenas os ônibus coletivos. A redução média foi de $0,51 \pm 0,44 d B(A)$.

No Cenário 4, em que a frota de veículos leves e pesados foi reduzida de $50 \%$, mantendo-se a velocidade em $60 \mathrm{~km} / \mathrm{h}$, o decréscimo do ruído é de $2,82 \pm 0,44 \mathrm{~dB}(\mathrm{~A})$. Já no Cenário 5 , no qual foi alterada a velocidade de tráfego para $40 \mathrm{~km} / \mathrm{h}$, a redução média foi $4,15 \pm 0,54 \mathrm{~dB}(\mathrm{~A})$.

Em todos cenários estudados, as intervenções nos modais de transporte não se mostraram suficientes para adequar o ruído ambiental ao nível critério, demostrando a necessidade da articulação abrangente e integrada do problema, com adoção de medidas mitigadoras do distúrbio sonoro por parte dos órgãos públicos e da comunidade.

A realização deste estudo encontrou dificuldades pela ausência de informações públicas disponíveis acerca do projeto do VLT da cidade de Cuiabá, o que levou a inferir decisões metodológicas que podem não ser as adotadas quando da implementação efetiva do VLT. A metodologia utilizada é passível de ser aplicada em outras situações urbanas, sendo que os resultados podem ser diferentes dependendo da condição de uso, ocupação do solo e morfologia urbana de outros locais em que aborda a espacialização do ruído. Apontam-se como trabalhos futuros, a necessidade de reavaliar o estudo após a implementação do VLT, para fins de verificação das necessidades de adequação na calibração do modelo, bem como das hipóteses adotadas.

\section{Agradecimentos}

Agradecemos à Fundação de Amparo à Pesquisa do Estado de Mato Grosso (FAPEMAT) pelo financiamento da pesquisa.

\section{REFERÊNCIAS}

ASSOCIAÇÃO BRASILEIRA DE NORMAS TÉCNICAS (ABNT). NBR 10151: Avaliação do nível do ruído em áreas habitadas visando o conforto da comunidade. Rio de Janeiro, 2000.

NBR 13067: Carro metropolitano e veículo leve sobre trilhos. Determinação dos níveis de ruídos. Método de ensaio. Rio de Janeiro, 1997a. 
NBR 13068: Ruído interno e externo em carro metropolitano e veículo leve sobre trilhos (VLT). Procedimento. Rio de Janeiro, 1997b.

NBR 13369: Cálculo simplificado do ruído equivalente contínuo $\left(\mathrm{L}_{\mathrm{eq}}\right)$. Rio de Janeiro, 1995.

BASTIÁN-MONARCA, N. A.; SUÁREZ, E.; ARENAS, J. P. Assessment of methods for simplified traffic noise mapping of small cities: casework of the city of Valdivia, Chile. Science of the Total Environment, v. 550, p. 439-448, 2016.

BISTAFA, S. R. Acústica aplicada ao controle de ruído. 2. ed. São Paulo: Edgard Blücher, 2011.

BRESSANE, A.; MOCHIZUKI, P. S.; CARAM, R. M.; J. A. F. ROVEDA, J. A. F. Sistema de apoio à avaliação de impactos da poluição sonora sobre a saúde pública. Cadernos de Saúde Pública, Rio de Janeiro, v. 32, n. 5, p.1-11, maio 2016.

BUNN, F.; ZANNIN, P. H. T. Urban planning- Simulation of noise control measures. Noise Control Engineering Journal, v. 63, n. 1, p. 1-10, 2015.

CANTIERI, E.; CATAI, R. E.; AgnOletto, R. A.; ZANQuetA, H. F. B.; Cordeiro, A. D.; ROMAnO, C. A. Elaboração de um mapa de ruído para a região central da cidade de Curitiba- PR. Revista Produção OnLine, Florianópolis, SC, v. 10, n. 1, p. 71-95, mar. 2010. Disponível em: <http://www.producaoonline.org.br/ index.php/rpo/article/view/239>.

CORTÊS, M. M.; NIEMEYER, M. L. O potencial da utilização da ferramenta de mapa de ruído em diferentes escalas de análise. Paranoá, Brasília, n. 11, p. 87-98, 2014.

CUIABÁ, Prefeitura Municipal [de]. Lei Municipal n. 3.819: dispõe sobre os padrões de emissão de ruídos, vibrações e outros condicionantes ambientais e dá outras providências. Cuiabá, 1999.

EUROPEAN COMMISSION WORKING GROUP ASSESSMENT OF EXPOSURE TO NOISE (WG-AEN). Guidance Note for Strategic Noise Mapping - Version 2. Wexford: Environmental Protection Agency, 2007. p. 1-129.

FIEDLER, P. E. K.; ZANNIN, P. H. T. Evaluation of noise pollution in urban traffic hubs-Noise maps and measurements. Environmental Impact Assessment, Review 51, 2015, p. 1-9 .

GARAVELLI, S. L.; COSTA, C. A.; CARVALHO JÚNIOR, E. B.; MAROJA, A. M. Impacto sonoro devido ao transporte rodoviário em Brasília, DF. In: CONGRESSO DE PESQUISA E ENSINO EM TRANSPORTES, 27., Belém. Anais... Belém: ANPET, 2013. p. 1-11.

GERGES, S. N. Y. Ruído: fundamentos e controle. 2. ed. Florianópolis: NR Editora, 2000.

GUEDES, I. C. M. Influência da forma urbana em ambiente sonoro: um estudo no bairro Jardins em Aracaju (SE). 2005. 126f. Dissertação (Mestrado em Engenharia Civil)- Faculdade de Engenharia Civil, Arquitetura e Urbanismo, Universidade Estadual de Campinas (UNICAMP), Campinas, SP, 2005.

JANIC, M.; VLEUGEL, J. Estimating potential reductions in externalities from rail-road substitution in TransEuropean freight transport corridors. Transportation Research Part D: Transport and Environment, v. 17, n. 2, p. 154-160, 2012.

LAGE, J. T. Níveis de ruído no interior de trens metropolitanos: caso São Paulo. 2003. 187f. Dissertação (Mestrado em Engenharia Civil) - Faculdade de Engenharia Civil, Universidade Estadual de Campinas (UNICAMP), Campinas, SP, 2003.

MAIA, M. A. L. Contribuição ao mapeamento do ruído urbano na cidade de Porto Alegre - RS. 2003. $126 f$. Dissertação (Mestrado em Engenharia) - Escola de Engenharia, Universidade Federal do Rio Grande do Sul, Porto Alegre, 2003. Disponível em: <http://hdl.handle.net/10183/2644>. Acesso em: 1o mar. 2016.

MARDONES, M. D. M. Mapeamento dos níveis de ruído em Copacabana, Rio de Janeiro, através de simulação computacional. 2009. 59p. Dissertação (Mestrado em Engenharia Mecânica)- Programa de Pósgraduação em Engenharia Mecânica, Universidade Federal do Rio de Janeiro (UFRJ), Rio de Janeiro, 2009.

MAROJA, A. M.; SANTOS, F. S., GARAVELLI, S. L., CARVALHO JÚNIOR, E. B. Veículo leve sobre trilhos: impacto ambiental acústico em Brasília-DF. In: CONGRESSO DE PESQUISA E ENSINO EM TRANSPORTES, 27. Anais... Belém: ANPET, 2013. p. 1-11. 
MATO GROSSO. Governo do Estado [de]. Anteprojeto do Veículo Leve sobre Trilho - VLT. Região Metropolitana do Vale do Rio Cuiabá. 2012. Disponível em: <http://www.mobilize.org.br/midias/pesquisas/ anteprojeto-do-veiculo-leve-sobre-trilho-de-cuiaba.pdf>. Acesso em: 03 set. 2017.

McALEXANDER, T. P.; GERSHON, R. R. M.; NEITZEL, R. L. Street-level noise in an urban setting: assessment and contribution to personal exposure. Environmental Health, v. 14, n. 18, p. 1-10, 2015.

MELO, R.; PIMENTEL, R.; SILVA, W.; LACERDA, D. Previsão do nível de ruído gerado pelo tráfego de veículos na cidade de João Pessoa, Brasil. In: CONGRESSO PAN-AMERICANO DE ENGENHARIA DE TRÁFEGO E TRANSPORTES E LOGÍSTICA, 16., 2010. Anais... Lisboa, 2010. p. 1-18.

MIRANDA, L. M. Trafego médio diário da Avenida Historiador Rubens de Mendonça (Avenida do CPA)Cuiabá-MT/Brasil. Apostila da disciplina de Transportes. Departamento de Engenharia Civil, Universidade Federal do Mato Grosso, 2009. 10p.

MIRANDA, R. S.; MACEDO, M. R. A. Mapa termoacústico da região continental de Belém-PA: um instrumento de planejamento em busca da qualidade ambiental. Revista GeoAmazônia, v. 1, n. 2, p. 8595, jan./jun. 2014.

NAGEM, M. P. Mapeamento e análise do ruído ambiental: diretrizes e metodologia. 2004. Dissertação (Mestrado em Engenharia Civil) - Faculdade de Engenharia Civil, Universidade Estadual de Campinas (UNICAMP), Campinas, SP, 2004.

NUNES, M. F. O. Poluição sonora em centros urbanos: o ruído de tráfego veicular. In: ENCONTRO NACIONAL DE ENGENHARIA DE PRODUÇÃO, 19., INTERNATIONAL CONGRESS OF INDUSTRIAL ENGINEERING, 5. \& ENCONTRO DE ENGENHEIROS DE PRODUÇÃO DA UFRJ, 2. Anais... Rio de Janeiro, 1999. p. 1-11.

PINTO, F. R.; GUEDES, M.; LEITE, M. J. Projecto-piloto de demonstração de mapas de ruído - escalas municipal e urbana. Lisboa: Instituto do Ambiente, 2004. 53p.

PINTO, D. N. Mapeamento acústico como ferramenta para predição do ruído urbano na área de influencia do estádio Arena das Dunas, Natal-RN. 2013. 126f. Dissertação (Mestrado em Arquitetura e Urbanismo) - Universidade Federal do Rio Grande do Norte (UFRN), Natal, RN, 2013.

RODRIGUES, F.; NASSI, C. D.; KAHN, S. Simulations of different configuration of modal split: Impacts on traffic noise in urban centers. In: INTERNATIONAL CONGRESS ON SOUND AND VIBRATION. $19^{\text {th }}, 2012$. Proceedings... ICSV, 2012. v. 4, p. 3090-9.

SANTOS, J. V.; MONTEIRO, S. B. S.; SILVEIRA JUNIOR, A.; RODRIGUES, S. G. VLT como elemento inovador do transporte público brasileiro. In: ENCONTRO NACIONAL DE ENGENHARIA DE PRODUCAO, 31. Anais... Belo Horizonte, 2011. p. 1-13.

SÃO PAULO. COMPANHIA DE SANEAMENTO DO ESTADO DE SÃO PAULO. CETESB L11032: Determinação do nível de ruído em ambientes internos e externos em áreas habitadas. São Paulo, 1992.

. COMPANHIA DE SANEAMENTO DO ESTADO DE SÃO PAULO. CETESB L11033: Instrução Técnica para aplicação da Norma Brasileira NBR 10.151. São Paulo, 1990.

SILVA, E. F. F. Alterações no clima acústico nas vizinhanças de uma rodovia devido a implantação de um modal de transporte. Publicação T. DM - 009/2015. Brasília, DF: Departamento de Engenharia Civil e Ambiental, Universidade de Brasília, 2015. 115p.

SILVA, F. P.; BERRÊDO, V. C. M.; OLIVEIRA, A. F.; TEIXEIRA JÚNIOR, W.; SANTOS, D. A. S.; SILVA, M. S. Avaliação de impacto ambiental: análise dos indicadores socioambientais na implantação do Veículo Leve sobre Trilhos (VLT). Revista Eletrônica da UNIVAR, v. 2, n. 14, 2015, p. $72-78$.

WORLD HEALTH ORGANIZATION (WHO). Environmental Noise. Copenhagen, Dinamarca: Regional Office for Europe, 2011.

Guidelines for Community Noise. BERGLUND, Birgitta; LINDVALL, Thomas; SCHWEL, Dietrich H. (Ed.). 1999. Disponível em: <http://www.who.int/docstore/peh/noise/guidelines2.html>. Acesso em: mar. 2016. 
ZANNIN, P. H. T.; SANT'ANA, D. Q. Noise mapping at different stages of a freeway redevelopment project - A case study in Brazil. Applied Acoustics, n. 72, p. 479-486, 2011.

\section{Sobre os autores:}

Adriana Eloá Bento Amorim: possui graduação em Arquitetura e Urbanismo (2003) e em Engenharia Civil pela Universidade Federal de Mato Grosso (1995); Especialização em Engenharia de Segurança do Trabalho (2003) pela UFMT, Mestrado em Engenharia Civil, na Área de Concentração em Arquitetura e Construção, pela Universidade Estadual de Campinas (2007). Tem experiência na área de Perícias Judiciais, Construção Civil e Conforto Ambiental, com ênfase em Acústica, atuando principalmente nos seguintes temas: perícias, patologia das edificações, materiais de construção; conforto ambiental; metodologia do projeto; projetos de prevenção e combate a incêndio e pânico; edificações sustentáveis; qualidade e produtividade de obra e segurança do trabalho. E-mail: adriana.eloa@terra.com.br

Luciane Cleonice Durante: Possui graduação em Engenharia Civil (1993), especialização em Engenharia de Segurança do Trabalho (1994), mestrado em Educação, linha Educação e Meio Ambiente (2000), pelo Instituto de Educação e doutorado em Física Ambiental, linha Conforto Ambiental, pela Universidade Federal de Mato Grosso (2012). Professora Adjunta III do Departamento de Arquitetura e Urbanismo, Coordenadora do Laboratório de Tecnologia e Conforto Ambiental (LATECA) do Departamento de Arquitetura e Urbanismo/FAET/UFMT e docente no Programa de Pós-graduação em Engenharia de Edificações e Ambiental (PPGEEA). Possui interesse pela área de sustentabilidade e meio ambiente, atuando principalmente nos seguintes temas: conforto ambiental e urbano e eficiência energética de edificações. E-mail: luciane.durante@hotmail.com

Jhonatha Correia Vilela: Graduando em Engenharia Civil, bolsista FAPEMAT 2013-2014 e CNPq 2014-2015. E-mail: jcvilela@gmail.com

Ivan Julio Apolônio Callejas: Graduado pela Universidade Federal de Mato Grosso (1995). Mestre na Universidade Estadual de Campinas, área de concentração Estruturas (1998). Doutor pelo programa de pós-graduação em Física Ambiental na área de conforto ambiental (2012). Professor Adjunto III da Universidade Federal de Mato Grosso, atuando no Departamento de Arquitetura e Urbanismo e no Curso de Pós-Graduação em Engenharia de Edificações e Ambiental (PPGEEA). Tem experiência na área de Engenharia Civil, com ênfase em desempenho termoenergético de edificações, conforto ambiental urbano, bioclimatologia, sensoriamento remoto urbano e estruturas metálicas. E-mail: ivancallejas1973@gmail.com 
